\title{
Electrophysiological effects of edrophonium in the innervated and the transplanted denervated human heart ${ }^{1}$
}

\author{
DALE R. STEMPLE, ROGER J. C. HALL2, JAY W. MASON, \\ AND DONALD C. HARRISON
}

From The Division of Cardiology, Stanford University School of Medicine, Stanford, California, USA

SUMMARY In order to determine the mechanism of action of edrophonium on the cardiac conduction system, we used His bundle recording and pacing techniques to examine the electrophysiological effect of edrophonium in 6 patients undergoing diagnostic evaluation for coronary artery disease and in 9 cardiac transplant recipients who were free of acute graft rejection. After control measurements were made of sinus cycle length, conduction intervals, and conduction system refractory periods, edrophonium was administered by constant intravenous infusion, and all electrophysiological measurements were repeated. In the normally innervated patients, edrophonium significantly increased sinus cycle length from $778 \pm$ $21 \mathrm{~ms}$ to $883 \pm 36 \mathrm{~ms}(\mathrm{P}<0.01)$, $\mathrm{AH}$ interval from $88 \pm 11 \mathrm{~ms}$ to $100 \pm 12 \mathrm{~ms}(\mathrm{P}<0.01)$, and $\mathrm{AV}$ nodal functional refractory period from $351 \pm 44 \mathrm{~ms}$ to $391 \pm 36 \mathrm{~ms}(\mathbf{P}<0.05)$. In the patients with transplanted hearts, edrophonium had no electrophysiological effect other than increasing the cycle length of the remnant recipient atrium from $722 \pm 21 \mathrm{~ms}$ to $798 \pm 31 \mathrm{~ms}(\mathrm{P}<0.01)$. We conclude that the electrophysiological effects of edrophonium in man are mediated primarily through autonomic innervation of the heart.

Edrophonium is a drug with brief anticholinesterase activity which is useful in the management of supraventricular tachyarrhythmias (Cantwell et al., 1972; Reddy et al., 1971). Though the drug has been used clinically for several decades, the specific electrophysiological effects of edrophonium have not been evaluated in humans.

Anticholinesterase agents produce their parasympathomimetic effects by inhibiting acetyl cholinesterase and allowing accumulation of acetyl choline released from nerve endings (Koelle, 1975). Many of these agents, however, also have important pharmacological effects that are at least partly independent of acetylcholinesterase inhibition. For example, the ability of anticholinesterases to reverse the neuromuscular blockade produced by curare is not quantitatively proportional to their anticholinesterase activity (Brimblecombe, 1974). Neostigmine can produce contraction in muscle depleted of anticholinesterase by chronic denervation (Riker and Wescoe, 1946) and neostigmine and

${ }^{1}$ This work was supported in part by an NIH grant and a Program Project grant.

'Dr Hall was supported by a British-American Research Fellowship of The American Heart Association and the British Heart Foundation. Received for publication 4 February 1977 physostigmine produce neuromuscular blockade in the rat phrenic nerve diaphragm preparation in the absence of acetylcholine accumulation (Thesleff, 1960). Edrophonium may also have a non-autonomically mediated direct cardiac effect, but this? possibility has not been studied.

In order to determine whether the electrophysiological effects of edrophonium are wholly dependent $ᄋ$ on cardiac autonomic innervation, we studied the effect of edrophonium on both the innervated and $\frac{9}{5}$ transplanted denervated human heart. Previous $\rightarrow$ investigations in cardiac transplant recipients have shown that their hearts remain functionally $N_{O}$ denervated and devoid of direct autonomic neural ${ }_{N}$ influences after transplantation (Cannom et al., $\mathcal{N}$ $1973,1975)$. Thus, the cardiac transplant recipient $\omega$ provides an opportunity to study the possibility of direct cardiac effects of edrophonium.

\section{Methods}

We performed electrophysiological studies in $15 \frac{\text { के }}{\mathrm{D}}$ patients after obtaining informed written consent. $\frac{\mathcal{P}}{\mathbb{Q}}$ At the time of study, all patients were in New York 0 Heart Association Functional Class I. None was receiving digitalis preparations, antiarrhythmic 8 
agents, or beta-blocking drugs. The 9 post-transplant patients were free from evidence of acute graft rejection or extracardiac disease, and the 6 normally innervated subjects were undergoing catheterisation for diagnostic evaluation of coronary artery disease.

Patients were catheterised in the postabsorptive state under sedation with oral diazepam. A 7F quadripolar recording-stimulating electrode catheter was positioned in the high right atrium for atrial pacing and recording of the right atrial electrogram. In the cardiac transplant patients, the catheter was positioned against the high anterolateral atrial wall to provide stable pacing of the donor atrium. A 7F tripolar or a $5 \mathrm{~F}$ bipolar electrode catheter was advanced across the tricuspid valve for His bundle recording. Three surface electrocardiographic leads (I, aVF, and V1) were recorded simultaneously with the intracardiac electrograms and transmitted to the AC input of an electrocardiographic amplifier with filter frequencies set between 40 and $500 \mathrm{~Hz}$. Pacing stimuli of $2 \mathrm{~ms}$ in duration were delivered by a programmable digital stimulator ( $M$. Bloom Associates, Ltd., Narberth, Pennsylvania) at an amperage twice the diastolic threshold. Data were recorded on photographic paper at $100 \mathrm{~mm} / \mathrm{s}$ paper speed on a Hewlett-Packard recorder, Model No. 4568C.

During cardiac transplantation the recipient heart is excised by division of the atria at their mid-level, leaving in situ the posterior walls of the right and left atria to which the donor atria are anastomosed (Stinson et al., 1969). Thus, the transplant patients have both donor and recipient activity which can be recorded by surface and intracardiac techniques (Fig. 1) (Stinson et al., 1972).

Baseline recordings of the $\mathrm{AH}$ and $\mathrm{HV}$ intervals and the sinus cycle length, including the recipient and donor sinus cycles in the transplant patients, were made at the spontaneous and base-paced heart rates (Rosen, 1972). The sinus node recovery time was measured twice after atrial pacing at cycle length of $430 \mathrm{~ms}$ for 1 minute, followed by abrupt termination of pacing. Atrial pacing was performed at decreasing cycle lengths of $400,375,350,330$, 315 , and $300 \mathrm{~ms}$ until Wenckebach conduction occurred. The maximal cycle length at which Wenckebach conduction was present was then determined within $5 \mathrm{~ms}$.

The atrial effective refractory period and the effective and functional refractory periods of the atrioventricular node were determined using the extra stimulus technique with an underlying paced rhythm (Rosen, 1972). The atrioventricular nodal effective refractory period was taken as the longest $A_{1} A_{2}$ interval at which $A_{2}$ was not conducted to the His-Purkinje system. The atrioventricular nodal functional refractory period was the shortest $\mathrm{H}_{1} \mathrm{H}_{2}$ interval obtained. The $\mathrm{AH}$ interval during rapid atrial pacing was recorded at the most rapid atrial rate at which there was one-to-one atrioventricular
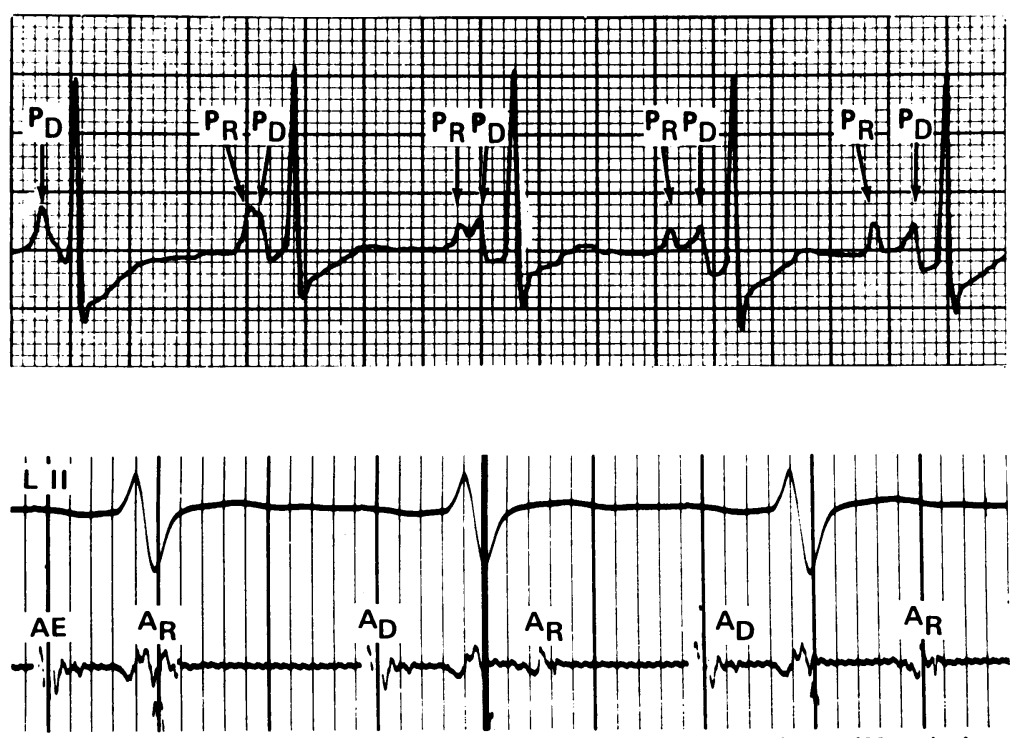
has a longer cycle length, as is usually seen under control conditions. Abbreviations: $D$, donor; $R$, recipient.
Fig. 1 Recordings illustrating the separate donor and recipient atrial activity seen in cardiac transplant recipients. In the upper panel the $P$ wave from the surface electrocardiogram gradually separates into two waves, $P_{\mathrm{D}}$ and $P_{\mathrm{R}} . P_{\mathrm{D}}$ is identified as the donor atrial activity because of its association with the $Q R S$ complex, and $P_{R}$ is the remnant recipient atrial activity which in this instance has a shorter cycle length. The lower panel shows the surface lead II (LII) and the atrial electrogram ( $A E$ ) from another transplant recipient. Again 2 different atrial waves are present. $A_{\mathrm{D}}$ is the donor atrial complex preceding the $Q R S$, and $A_{\mathrm{R}}$ is the recipient atrial activity which 
conduction both before and after drug administration.

Edrophonium has a brief duration of action, because of the reversibility of its binding to acetylcholinesterase (Brimblecombe, 1974). Because of the transient effect of a single intravenous dose of edrophonium, we have used a constant infusion of the drug to obtain a stable condition for electrophysiological measurements (Frieden et al., 1971).

After resting control measurements were completed, each patient was given a test dose of 0.03 $\mathrm{mg} / \mathrm{kg}$ of edrophonium, followed 1 minute later by an additional bolus of $0.07 \mathrm{mg} / \mathrm{kg}$ and a constant intravenous infusion of $0.14 \mathrm{mg} / \mathrm{kg}$ per min. The drug was infused for 10 minutes to achieve a stable condition. Then during continuous edrophonium infusion, electrophysiological measurements were repeated, using the previous base-pacing cycle length.

A double dose of edrophonium was administered to 1 subject with normal cardiac innervation and 2 transplant recipients; baseline measurement and edrophonium administration were performed as outlined above. Conduction intervals were determined at this first dose of edrophonium, but before pacing studies a second bolus of $0.1 \mathrm{mg} / \mathrm{kg}$ was given, and the infusion rate was increased to $0.028 \mathrm{mg} / \mathrm{kg}$ per min. After a further 10-minute stabilisation period, electrophysiological measurements were repeated.

All data reported are those obtained at the highest dose of edrophonium. Statistical comparison of results before and during edrophonium was performed using Student's t test for paired data. A linear regression analysis of the $\mathrm{H}_{1} \mathrm{H}_{2}$ interval versus $A_{1} A_{2}$ interval plots in Fig. 2 and 3 was performed to obtain slope and intercept for each group of patients. An unpaired t test was then used to test for significant differences in the derived slopes and intercepts.

\section{Results}

\section{INNERVATED PATIENTS}

The electrophysiological effects of edrophonium in the 6 innervated patients are summarised in Table 1. Mean sinus cycle length was increased 13 per cent from $778 \pm 21$ to $883 \pm 36 \mathrm{~ms} \quad(P<0.01)$. Atrial effective refractory period was not significantly changed.

Atrioventricular nodal conduction was slowed and refractoriness increased. The mean $\mathrm{AH}$ interval increased from $88 \pm 11 \mathrm{~ms}$ to $100 \pm 12 \mathrm{~ms}$ $(\mathbf{P}<0.01)$. The $\mathrm{AH}$ interval during rapid atrial pacing increased from $133 \pm 22 \mathrm{~ms}$ to $156 \pm 23 \mathrm{~ms}$ $(\mathbf{P}<0.05)$, at a mean pacing cycle length of $372 \mathrm{~ms}$.
The mean maximum paced cycle length at which Wenckebach conduction was present increased from $\leftarrow$ $302 \pm 22 \mathrm{~ms}$ to $359 \pm 28 \mathrm{~ms}$. Thus the mean maxi- $\overrightarrow{\vec{c}}$ mum ventricular rate achieved decreased from $199-\frac{7}{0}$ to 167 with administration of edrophonium.

The mean atrioventricular nodal effective refrac- $\frac{\overline{\bar{c}}}{\overline{0}}$ tory period was not significantly altered but the $\widetilde{\Phi}$ mean atrioventricular nodal functional refractory period was prolonged by edrophonium from ${ }^{\mathrm{c}}$ $351 \pm 44 \mathrm{~ms}$ to $391 \pm 36 \mathrm{~ms}(\mathbf{P}<0.05)$. There was no $\vec{\circ}$

Table 1 Effects of edrophonium on innervated patients

\begin{tabular}{|c|c|c|c|c|}
\hline & Control & Edrophonium & No. & $P$ \\
\hline \multicolumn{5}{|l|}{ Studies at rest } \\
\hline Atrial cycle length & $778 \pm 21$ & $883 \pm 36$ & 6 & $<0.01$ \\
\hline AH interval & $88 \pm 11$ & $100 \pm 12$ & 6 & $<0.01$ \\
\hline HV interval & $42 \pm 2$ & $41 \pm 2$ & 6 & NS \\
\hline QRS duration & $82 \pm 4$ & $83 \pm 5$ & 6 & NS \\
\hline \multicolumn{5}{|l|}{ Pacing studies } \\
\hline $\mathrm{AH}$ interval during & & & & \\
\hline \multirow{2}{*}{\multicolumn{5}{|c|}{$\begin{array}{l}\text { Longest cycle length } \\
\text { with Wenckebach }\end{array}$}} \\
\hline & & & & \\
\hline $\begin{array}{l}\text { conduction } \\
\text { Sinus node recovery time }\end{array}$ & $302 \pm 22$ & $359 \pm 28$ & 6 & $<0.05$ \\
\hline \multicolumn{5}{|c|}{ Refractory periods } \\
\hline Atrial ERP & $240 \pm 22$ & $248 \pm 24$ & 6 & NS \\
\hline \multicolumn{5}{|l|}{ Atrioventricular node } \\
\hline $\begin{array}{l}\text { ERP } \\
\text { Atrioventricular node }\end{array}$ & $263 \pm 27$ & $290 \pm 33$ & 6 & NS \\
\hline \multicolumn{2}{|l|}{ Atrioventricular node } & $391 \pm 36$ & 5 & \\
\hline
\end{tabular}

All intervals given as the mean \pm standard error of the mean in milliseconds. ERP, effective refractory period; FRP, functional refractory period.

Table 2 Effects of edrophonium on transplanted denervated patients

\begin{tabular}{|c|c|c|c|c|}
\hline & Control & Edrophonium & No. & $P$ \\
\hline \multicolumn{5}{|l|}{$\begin{array}{l}\text { Studies at rest } \\
\text { Recipient atrial cycle }\end{array}$} \\
\hline length & $722 \pm 21$ & $798 \pm 31$ & 6 & $<0.01$ \\
\hline Donor atrial cycle length & $664 \pm 35$ & $674 \pm 38$ & 7 & NS \\
\hline $\mathrm{AH}$ interval & $86 \pm 6$ & $85 \pm 6$ & 9 & NS \\
\hline HV interval & $43 \pm 4$ & $43 \pm 3$ & 9 & NS \\
\hline QRS duration & $101 \pm 8$ & $103 \pm 7$ & 9 & NS \\
\hline \multirow{2}{*}{\multicolumn{5}{|c|}{$\begin{array}{l}\text { Pacing studies } \\
\text { AH interval during }\end{array}$}} \\
\hline & & & & \\
\hline $\begin{array}{l}\text { rapid pacing } \\
\text { Longest cycle length }\end{array}$ & $122 \pm 6$ & $122 \pm 7$ & 9 & NS \\
\hline $\begin{array}{l}\text { with Wenckebach } \\
\text { conduction }\end{array}$ & $324 \pm 16$ & $331 \pm 17$ & 8 & NS \\
\hline $\begin{array}{l}\text { Sinus node recovery time } \\
\text { Refractorv periods }\end{array}$ & $976 \pm 124$ & $903 \pm 79$ & 8 & NS \\
\hline $\begin{array}{l}\text { Refractorv periods } \\
\text { Atrial ERP }\end{array}$ & $229 \pm 18$ & $236 \pm 15$ & 8 & NS \\
\hline Atrioventricular node & $290 \pm 14$ & $301 \pm 11$ & 6 & NS \\
\hline $\begin{array}{l}\text { Atrioventricular node } \\
\text { FRP }\end{array}$ & $354 \pm 15$ & $355 \pm 13$ & 8 & NS \\
\hline \multicolumn{5}{|l|}{ For explanation see Table 1.} \\
\hline
\end{tabular}


evidence of altered His-Purkinje conduction since the mean HV interval and QRS configuration and duration were unchanged.

\section{TRANSPLANT PATIENTS}

Table 2 summarises the effect of edrophonium in the denervated hearts. Whereas the spontaneous recipient atrial cycle length was increased from 722 $\pm 21 \mathrm{~ms}$ to $798 \pm 31 \mathrm{~ms} \quad(P<0.01)$, the resting donor atrial cycle length and atrial effective refractory period were unaffected. There was no change in the $\mathrm{AH}$ interval during spontaneous rhythm and rapid pacing, the longest pacing cycle length showing Wenckebach conduction and the atrioventricular nodal refractory periods. As in the innervated patients, His-Purkinje conduction remained unchanged.

Fig. 2 illustrates the mean $\mathrm{H}_{1} \mathrm{H}_{2}$ interval at each $\mathrm{A}_{1} \mathrm{~A}_{2}$ interval for both the control and transplant patients before drug administration. Each point represents the mean for at least 4 patients for which data at the given $A_{1} A_{2}$ interval ( $\pm 5 \mathrm{~ms}$ ) were available. The values for the control and transplant groups give linear regression curves $(R=0.829$ and $R=0.968$, respectively) which are significantly

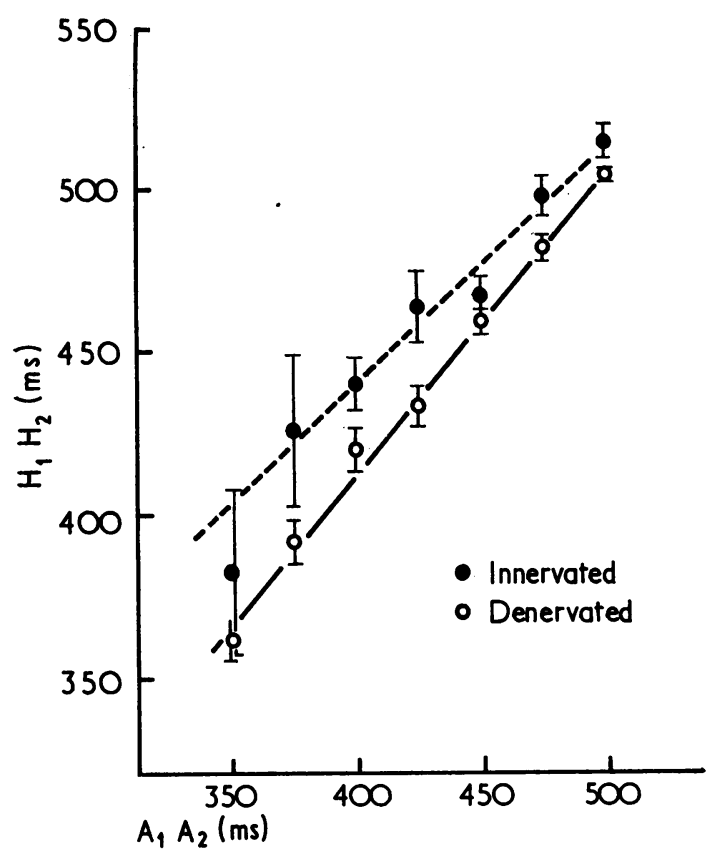

Fig. $2 A$ plot of the mean $H_{1} H_{2}$ and $A_{1} A_{2}$ intervals in innervated and denervated patients. The innervated patients have significantly longer $\mathrm{H}_{1} \mathrm{H}_{2}$ intervals consistent with the influence of resting vagal tone. See text for details. different in slope and intercept $(P<0.01)$. The lower position of the refractory curve in the transplant patients is consistent with their lack of resting vagal tone.

Fig. 3 shows the change in mean $\mathrm{H}_{1} \mathrm{H}_{2}$ response during edrophonium infusion. The linear regression curves in the innervated patients before $(R=0.829)$ and during $(R=0.874)$ edrophonium are not significantly different, but two individual data points at a premature $A_{1} A_{2}$ interval of $375 \mathrm{~ms}$ and $450 \mathrm{~ms}$ show a significant prolongation of $\mathrm{H}_{1} \mathrm{H}_{2}$ with edrophonium $(P<0.05)$. There were no significant differences in the transplant patients before and after edrophonium.

\section{SIDE EFFECTS}

The known side-effects of edrophonium include nausea, abdominal pain, sweating, muscle fasciculations, visual blurring, increased bronchial secretions, and salivation (Randall et al., 1955). Only 5 of our 15 patients experienced no side effects ( 3 from the innervated group and 2 from the denervated group). The other 11 patients all noted

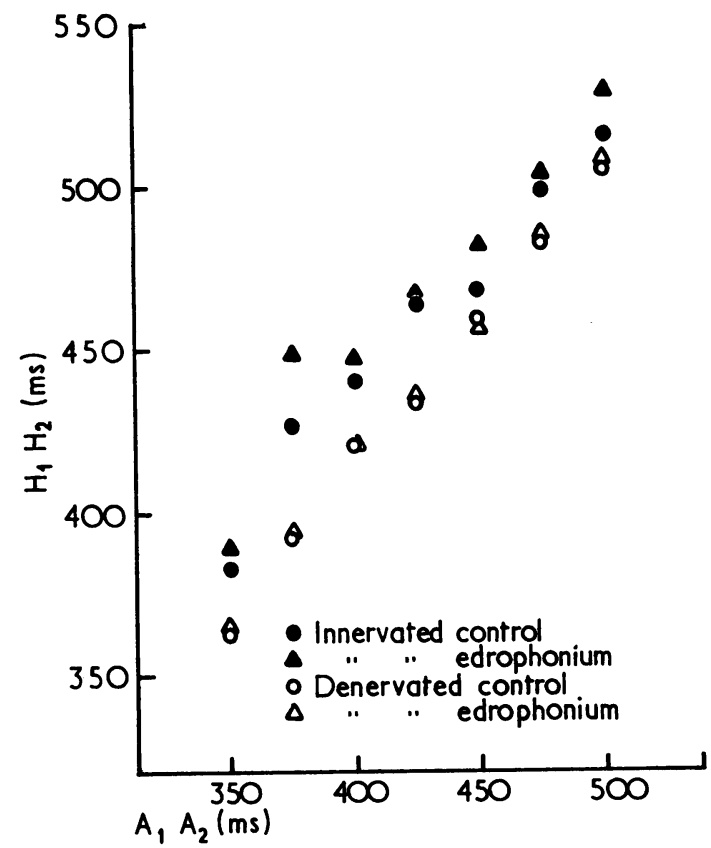

Fig. 3 The effect of edrophonium on the mean $\mathrm{H}_{1} \mathrm{H}_{2}$ interval at various premature $A_{1} A_{2}$ intervals in the innervated and denervated patients. Edrophonium has no effect on the denervated group of patients, but tends to prolong the $\mathrm{H}_{1} \mathrm{H}_{2}$ intervals in the innervated group. See text for details. 
at least mild nausea. In addition, 1 had stomach cramps, 2 complained of a tingling sensation in the lower extremities, and 5 became diaphoretic. In no patient were the side effects severe enough to stop the study.

\section{Discussion}

Our results show that, at the dosage used in this study, the effects of edrophonium on the cardiac conducting system are solely autonomically mediated; no direct effect of edrophonium on the denervated human heart could be detected. Slowing of the innervated recipient atrial rate in the transplant patient group indicates that a pharmacologically active dose of the drug was administered. However, the possibility that a higher dose may have significant, direct electrophysiological effects cannot be excluded.

The electrophysiological effects of edrophonium which we determined in this study are consistent with the known effects of cardiac parasympathetic stimulation: slowing of the sinoatrial rate, decrease of atrioventricular nodal conduction velocity, and increase in atrioventricular nodal refractoriness (Higgins et al., 1973). These effects are also in keeping with the cardiac distribution of cholinergic fibres which are richly supplied to the sinoatrial and atrioventricular nodal areas. Though cholinergic fibres have also been shown to supply the ventricular specialised conducting system, their experimentally measurable effect has been primarily on the ventricular fibrillation threshold rather than conduction velocity per se (Kent et al., 1974). The lack of any measured effect of edrophonium in the denervated heart suggests the absence of any functionally active post-ganglionic cholinergic fibres. Thus, there is no local accumulation of acetylcholine to produce the parasympathomimetic effect seen in the innervated heart.

In patients subjected to remeasurement of atrioventricular nodal refractory periods, the functional refractory period has been reported to vary significantly with time (Reddy et al., 1975). Our finding that the atrioventricular nodal functional refractory period was affected by edrophonium more than the atrioventricular nodal effective refractory period suggests that the functional refractory period is more susceptible to autonomic influences, which may account for its previously observed spontaneous variation.

The slow rate of the normally innervated heart compared with the rapid resting rate of the denervated heart is consistent with a predominantly parasympathetic effect of resting autonomic tone.
The present study provides further evidence for the predominant influence of resting vagal tone in the innervated heart. Fig. 2 shows a significantly larger $\mathrm{H}_{1} \mathrm{H}_{2}$ interval for each premature stimulus interval in the innervated group of patients compared with the denervated group. Thus, under control conditions, at any given premature pacing interval $\left(A_{1} A_{2}\right)$ there is a slower conduction of the premature stimulus (longer $\mathrm{A}_{2} \mathrm{H}_{2}$ ) in the innervated patients. ${ }^{1}$ This slowed conduction is characteristic of enhanced parasympathetic stimulation (Higgins et al., 1973).

Kolman et al. (1975) have emphasised that the effect of a vagotonic intervention is influenced greatly by pre-existing autonomic tone. For example, vagal stimulation increases ventricular fibrillation threshold only during a period of increased sympathetic activity. Similarly, the electrophysiological effects of edrophonium may be more pronounced when the resting sympathetic input is raised, and less pronounced in a state of low sympathetic tone.

The duration of action of a single intravenous bolus of edrophonium is brief because of its competitive displacement from acetylcholinesterase by acetylcholine (Brimblecombe, 1974). In this investigation, we assumed that a stable condition was achieved by administration of a loading bolus of edrophonium followed by a 10-minute infusion. However, plasma concentrations of edrophonium were not measured to document a steady-state condition. Previous studies in normal Wistar rats showed the plasma half-life of the slow disposition phase of edrophonium elimination to be 68 minutes (Back and Calvey, 1974). On this basis, prolonged infusion of the drug could possibly cause accumulation and toxic plasma levels. However, in our studies, no late toxicity was noted during constant intravenous infusion of up to one hour in duration.

This investigation describes the electrophysiological effect of edrophonium on the innervated human heart and shows that an identical dose produces no significant effect in the transplanted denervated heart, confirming for the first time that the cardiac conduction system effects of edrophonium in man are mediated by autonomic innervation of the heart.

\section{References}

Back, D. J., and Calvey, T. N. (1974). The pharmacokinetics of [14C]-edrophonium in normal Wistar rats and homozygous Gunn rats with ligated renal pedicles. British Fournal of Pharmacology, 51, 61-65.

Brimblecombe, R. W. (1974). Drug Actions on Cholinergic Systems. University Park Press, Baltimore, Maryland.

'since $\mathrm{H}_{2} \mathrm{H}_{2}=\mathrm{A}_{2} \mathrm{~A}_{2}+\mathrm{A}_{2} \mathrm{H}_{8}-\mathrm{A}_{1} \mathrm{H}_{2}$ 
Cannom, D. S., Graham, A. F., and Harrison, D. C. (1973). Electrophysiological studies in the denervated transplanted human heart: response to atrial pacing and atropine. Circulation Research, 32, 268-278.

Cannom, D. S., Rider, A. K., Stinson, E. B., and Harrison, D. C. (1975). Electrophysiologic studies in the denervated transplanted human heart. II. Response to norepinephrine, isoproterenol and propranolol. American fournal of Cardio$\log y, 36,859-866$.

Cantwell, J. D., Dawson, J. E., and Fletcher, G. F. (1972). Supraventricular tachyarrhythmias, treatment with edrophonium. Archives of Internal Medicine, 130, 221-226.

Frieden, J., Cooper, J. A., and Grossman, J. I. (1971) Continuous infusion of edrophonium (Tensilon) in treating supraventricular arrhythmias. American fournal of Cardiology, 27, 294-297.

Higgins, C. B., Vatner, S. F., and Braunwald, E. (1973) Parasympathetic control of the heart. Pharmacological Reviervs, 25, 119-155.

Kent, K. M., Epstein, S. E., Cooper, T., and Jacobowitz, D. M. (1974). Cholinergic innervation of the canine and human ventricular conducting system. Circulation, 50, 948-955.

Koelle, G. B. (1975). Anticholinesterase agents. In The Pharmacological Basis of Therapeutics, 5th ed., pp. 445-466. Ed. by L. Goodman and A. Gilman. MacMillan, New York.

Kolman, B. S., Verrier, R. L., and Lown, B. (1975). The effect of vagus nerve stimulation upon vulnerability of the canine ventricle. Role of sympathetic-parasympathetic interactions. Circulation, 52, 578-585.

Randall, L. O., Conroy, C. E., Ferruggia, T. M., Kappell, B. H., and Knoeppel, C. R. (1955). Pharmacology of the anticholinesterase drugs-Mestinon, Prostigmin, Tensilon, and TEPP. American fournal of Medicine, 19, 673-678.

Reddy, C. P., Damato, A. N., Akhtar, M., Ogunkelu, J. B., Caracta, A. R., Ruskin, J. N., and Lau, S. H. (1975). Time dependent changes in the functional properties of the atrioventricular conduction system in man. Circulation, 52, 1012-1022.

Reddy, R. C. V., Gould, L., and Gomprecht, R. F. (1971). Use of edrophonium (Tensilon) in the evaluation of cardiac arrhythmias. American Heart fournal, 82, 742-749.

Riker, W. F., and Wescoe, W. C. (1946). The direct action of prostigmine on skeletal muscle: its relationship to the choline esters. Fournal of Pharmacology and Experimental Therapeutics, 88, 58-66.

Rosen, K. M. (1972). Evaluation of cardiac conduction in the cardiac catheterization laboratory. American fournal of Cardiology, 30, 701-703.

Stinson, E. B., Dong, E., Iben, A. B., and Shumway, N. E. (1969). Cardiac transplantation in man. III. Surgical aspects. American fournal of Surgery, 118, 182-186.

Stinson, E. B., Schroeder, J. S., Griepp, R. B., Shumway, N. E., and Dong, E. (1972). Observations on the behaviour of recipient atria after cardiac transplantation in man. American fournal of Cardiology, 30, 615-622.

Thesleff, S. (1960). Supersensitivity of skeletal muscle produced by botulinum toxin. Fournal of Physiology, 151, 598-607.

Requests for reprints to Dr Jay W. Mason, Division of Cardiology, Stanford University Medical Center, Stanford, California 94305, USA. 